\title{
ACTYBOSS: Activity, Behavioral Therapy in Young Subjects - After-School Intervention Pilot Project on Obesity Prevention
}

\author{
Bartolome Burguera ${ }^{a, b} \quad$ Antoni Colom ${ }^{b}$ Estefanía Piñero ${ }^{b} \quad$ Aina Yanez $^{b} \quad$ Maria Caimari $^{c}$ \\ Juan Tur $^{\mathrm{b}}$ Marga Frontera $^{\mathrm{b}}$ Marta Couce $^{\mathrm{b}}$ Esther Cardo $^{\mathrm{d}}$ Antoni Aguiló $^{\mathrm{e}}$ Antoni Burguera $^{\mathrm{b}}$ \\ Elena Cabeza ${ }^{f}$ \\ a Division of Endocrinology, \\ bIUNICS-CAIBER, \\ ${ }^{\mathrm{C}}$ Division of Pediatrics, University Hospital Son Espases, \\ ${ }^{d}$ Neuroscience Laboratory (IUNICS) and Neuropediatrics, Hospital Son Llàtzer, \\ e University of Illes Balears, \\ ${ }^{f}$ Conselleria de Salut, Govern Illes Balears, Palma de Mallorca, Spain
}

\author{
Keywords \\ Obesity · Children · Prevention · Exercise $\cdot$ Incentive . \\ Nutrition · Healthy lifestyle
}

\section{Summary}

Aims: To test the feasibility of a school-based intervention, which combines an incentive-driven physical activity program with lifestyle lectures, and its potential beneficial outcome on children's metabolic parameters. Methods: We conducted a 6-month pilot intervention in two high schools in Mallorca, Spain, consisting of a program which involved free supervised exercise sessions and nutritional lectures, where children received credit points as a reward for the hours spent exercising and attendance to the lectures. The credit-earned points obtained were exchanged for gifts. We developed personalized cards and a web application for the participants to check the gifts they were eligible for (www.actyboss. com). Percentage body fat, percentage of fat-free mass and BMI were measured. Secondary measures included fitness parameters, blood pressure and blood lipids levels. 90 children signed up the consent form and 56 completed the program until the endpoint. Results: We found a beneficial effect on body composition, fitness parameters, and systolic blood pressure in children who participated in ACTYBOSS compared to children who did not start the intervention. Conclusions: We describe the incentive-driven, after-school intervention pilot pro- gram to promote physical activity and a healthy lifestyle. The program had a positive effect on anthropometric measurements. A larger incentive-driven healthy lifestyle program is now ongoing.

\section{Introduction}

Spain has the second highest number of obese children in Europe. $26 \%$ of our children are obese or overweight [1], and the prevalence of obesity in our country has doubled over the last 15 years. Therefore, obesity and overweight are one of the most significant health threats to our children [2].

Interventions aiming to increase physical activity and to improve nutrition are the foundation of any initiative to prevent childhood obesity, and it seems evident that schools, being the institution with the higher contact time with children, are the logical site for these actions [3]. What is not clear, however, is how these efforts should be structured and implemented to achieve maximum effect.

Although the existing research studies provide no definitive answers about optimal intervention designs [4-8], the authors of the Community Preventive Services Task Force review and the ADA review concluded that school-based interventions to prevent and control obesity should be multi-component in nature and address nutrition, physical activity, and

\section{KARGER \\ Fax +497614520714 \\ Information@Karger.de}

www.karger.com (c) 2011 S. Karger GmbH, Freiburg

$1662-4025 / 11 / 0045-0400 \$ 38.00 / 0$

Accessible online at:

www.karger.com/ofa
Barto Burguera MD, PhD

Research Unit/CAIBER, IUNICS, 1er piso Edificio S

Hospital Universitario Son Espases

Ctra. Valldemossa 79, C.P 07010 Palma, Spain

Tel. +34871205000

bartolome.burguera@ssib.e 
sedentary behaviors [9-11]. However, it is important to realize that schools are faced with multiple curriculum mandates and limited financial and staff resources. In addition, children are usually asked by parents or school officials to increase physical activities during an age that is characterized by confrontational attitudes with important peer influences [6], which translates into poor adherence [12].

Given these circumstances, it seems clear that effective, cost-efficient and innovative strategies to prevent obesity in the school setting which emphasize adherence are urgently needed. One attractive approach to increase physical activity in adolescents is to provide physical and social activities through structured, incentive-driven after-school programs.

The objective of the present study was to determine the feasibility and impact that an incentive-driven, innovative after-school pilot intervention, which combines an exercise program with nutritional lectures, may have on improving body composition and physical fitness. Our intervention was based on a paradigm that assumes pediatric obesity to be mainly due to inadequate amounts of physical activity. It was our intention to motivate children to start a physical activity program and learn about the benefits of adopting a healthy lifestyle.

\section{Material and Methods}

ACTYBOSS (Activity, Behavioral Therapy in Young Subjects) is an incentive-driven physical activity and nutrition education program for children (11-14 years old) in an after-school setting designed to prevent the development of obesity.

\section{Schools, Subjects and Ethical Approval}

Three public schools were invited to participate, and two of them (I.E.S. Berenguer d'Anoia, Inca and I.E.S. Bendinat, Calvià) agreed to take part in this pilot study. The grades involved in the study were 1st, 2nd and 3rd grade of ESO (Obligatory Secondary School of Spain) which correspond to 7 th, 8 th, 9th grade in the USA. In order to be eligible to enroll, students could not be members of any federated sport team or organized after-school sport activities. They had to agree to have two blood samples drawn (before and after the intervention) and plan to complete the school year in the same high school. Written informed consent was obtained from participants and their parents. The study design was approved by the Balearic Islands Ethical Committee.

\section{Study Design}

The intervention involved nutritional advice, behavioral modification, and free supervised physical activity sessions, where children received points as a reward for the hours they spent exercising and also for their attendance to nutritional lectures. The credit-earned points obtained could be exchanged for sport equipment, trips, gym subscriptions, or lei-

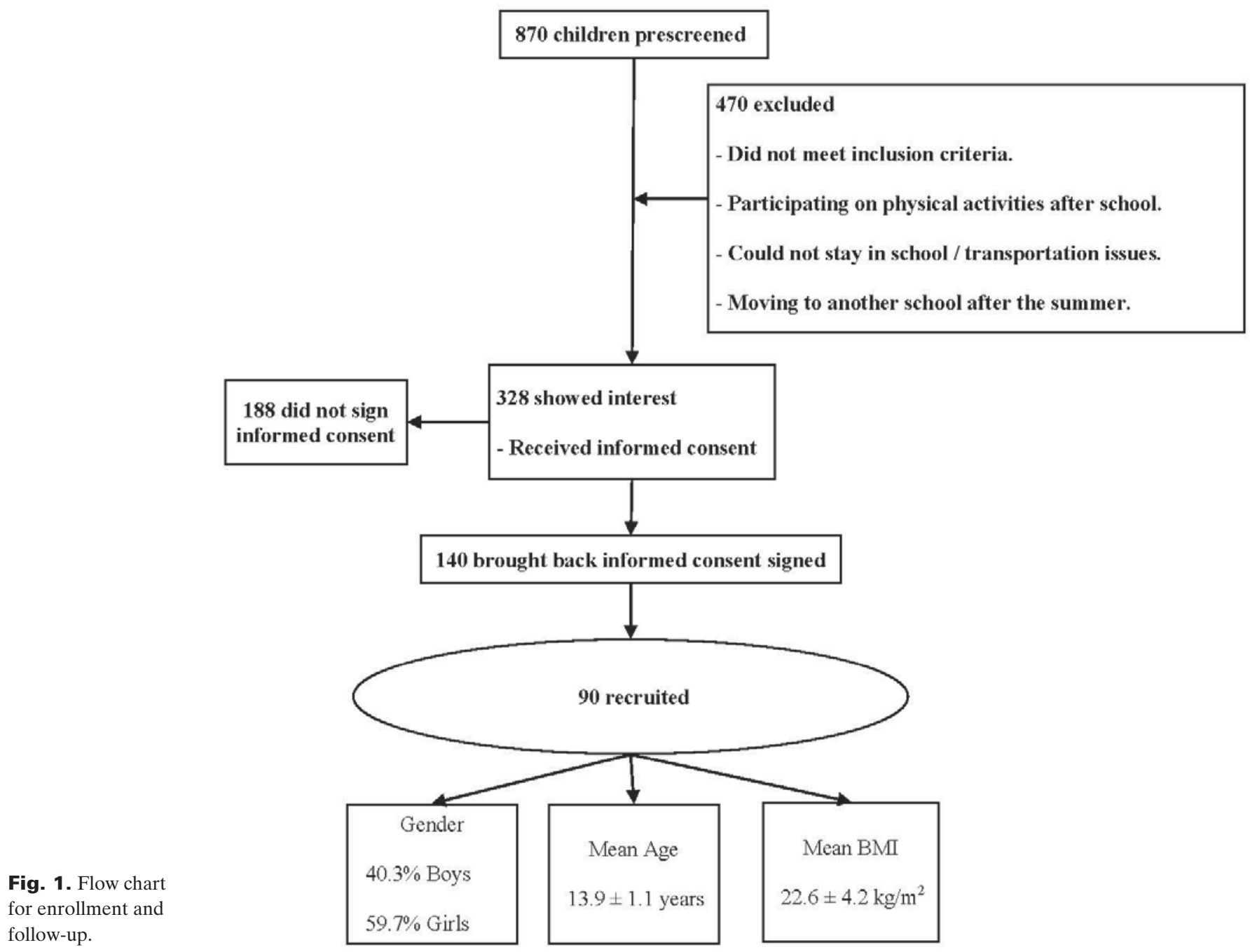
follow-up. 
sure and sport events tickets. We have developed personal ID-cards (with an assigned code) and a web application for children and parents as well as exercise monitors to check the points accumulated and the gifts they were eligible to (www.actyboss.com). We have identified a significant list of sponsors interested in supporting our project. These companies provide free merchandise in exchange for publicity throughout the ACTYBOSS program and our webpage. The gifts included entrance tickets for sport events, sport equipment, trips, entrance tickets for leisure parks, cinema and bowling tickets, and others.

\section{Nutritional Advice}

Participants were offered 2 nutritional and 2 behavioral modification workshops during the intervention period. The topics were:

i) How to eat healthy?

ii) Influence of the mass media on what we eat.

iii) Impact of physical activity on body and brain development.

iv) Build up our self esteem. Children received 100 points for each session they attended to.

\section{Physical Activity and Fitness Evaluation}

The children had the opportunity to participate in enjoyable, noncompetitive sports and physical activities. The program had an important social component, and it was encouraged by the incentive of being eligible to receive gifts, based on the degree of participation on the exercise activities.

The ACTYBOSS exercise tool box included team sports, racket games as well as dancing and music games. The activity was free, supervised by physical education (PE) instructors and scheduled 15 min after their regular school classes ended. The maximum exposure to the activity offered was $3 \mathrm{~h}$ every day, Monday through Thursday (divided into two periods of $90 \mathrm{~min}$ ) and was offered in their school sport facilities. Children received one point for each minute they participated in the activity. The PE instructors got paid on an hourly basis with funds from the Conselleria de Salut. We put special emphasis on motivating and informing the children about the benefits of a healthy lifestyle, highlighting the fact that they needed to be responsible for their own health. Children underwent a battery of tests included in the Eurofit test before and after the intervention to evaluate their skill-related fitness as previously described [13]. It included evaluation of: speed, agility, coordination, and flexibility.

\section{Parental Conferences}

We offered 2 nutritional conferences to the parents/tutors during the 6 months that the intervention lasted. The topics were:

i) How to cook a healthy meal?

ii) Benefits of the Mediterranean diet.

Children received 200 points for each session that their parents/tutors attended to.

\section{Physical Exam and Anthropometry}

All children underwent a general physical exam. A full set of anthropometric and body composition measurements were collected at baseline and at 6-month follow-up. Height was measured using a commercial mobile stadiometer, and weight was measured using a flat electronic weighing scale (SECA 888, Kent, UK). Waist circumference was measured over the naked skin, half-way between the lower rib and the top of the iliac crest. Two measurements were obtained, and the average was recorded. Bioelectrical impedance was measured in duplicate with a single-frequency tetrapolar plethysmograph (Tanita Body Composition Analyzer; Biologica SL, Barcelona, Spain).

We chose percentage of body fat (\% BF) as our main outcome measurement, because it is more closely related to many cardiometabolic risk factors than is a weight index such as BMI. In addition, due to the fact that an intervention that emphasizes physical activity might increase fat-

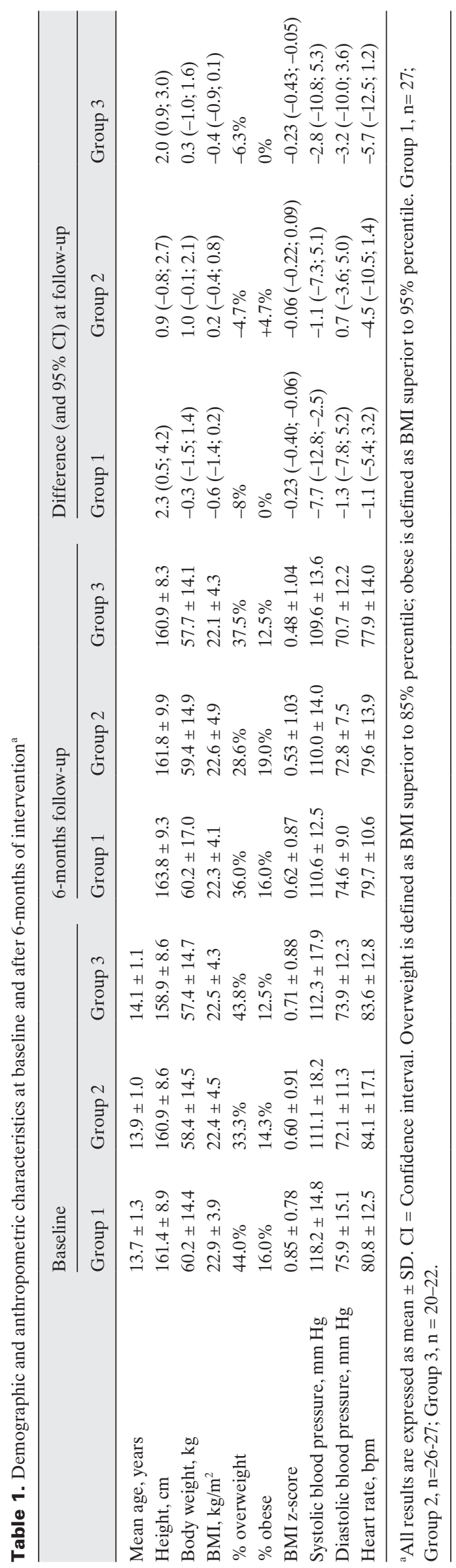

Burguera/Colom/Piñero/Yanez/Caimari/Tur/ Frontera/Couce/Cardo/Aguiló/Burguera/ Cabeza 
A

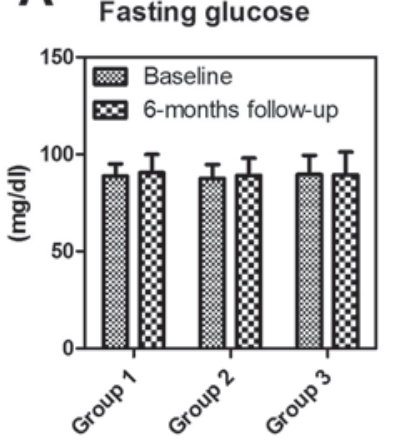

B

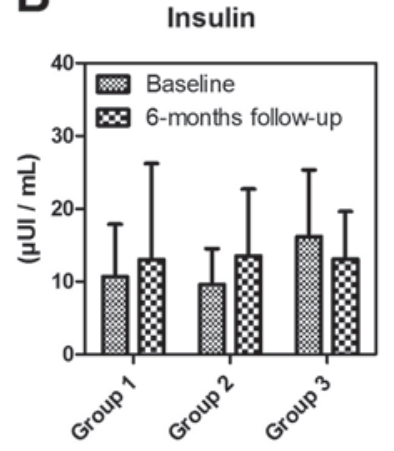

C нома-IR

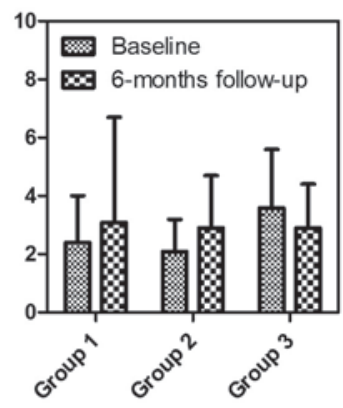

glucose, insulin and HOMA results.
glune and 6-month follow-

free mass at the same time that it decreases fat mass [14], it is possible for BMI to provide misleading results [15]. Other relevant body composition measurements provided by bioimpedance included percentage of fat-free mass.

\section{Blood Test}

Testing included blood work to determine cell blood count, biochemistry (indicate), fasting glucose and hormonal determinations: insulin, TSH, $\mathrm{GH}$, and testosterone (in boys) or estrogens (in girls) prior to beginning the program and at completion of the intervention. Fasting plasma glucose and insulin levels were used to calculate the insulin resistance by the Homeostasis Model Assessment index (HOMA-IR). HOMA-IR was calculated using the formula: fasting serum insulin $(\mathrm{U} / \mathrm{ml}) \times$ fasting serum glucose (mmol/1) / 22.5

A 40-ml fasting blood sample was obtained from an antecubital vein. Samples were prepared using low-speed centrifugation at $4,000 \times g$ for $10 \mathrm{~min}$.

\section{Sponsors}

Decathlon, Fundación RCD Mallorca, Aspro Ocio, Global Hoteles, Iscomar, Sportmach, Hoteles Marriot, Coca-Cola, McDonalds, LaccaoAgama, Quely, Centros Illes Wellness.

\section{Statistical Analysis}

Results are presented as mean \pm standard deviation (SD). Continuous variables are analyzed using ANOVA, whereas categorical variables are analyzed using the $\chi^{2}$ test. Non-parametric test (Kruskal-Wallis) was used for variables that were not normally distributed. A p value lower than 0.05 was considered statistically significant. All statistical analysis was performed using SPSS v.15.0.

\section{Results}

A flow chart for enrollment and follow-up is presented in figure 1. Each high school class had an average of 25-30 students, and we offered participation on this project to a total of 870 children. However 470 (54\%) did not meet inclusion criteria. 328 children showed interest in our program and received the informed consent. Of these, 140 children brought back the informed consent (IC) signed by their legal guardians. $40 \%$ of children who did not bring the IC admitted that having a blood drawn was the main reason for their lack of engagement in the study, and $33 \%$ of them did not meet inclusion criteria because they were already included on after- school federated-team sport activities. 50 children, after signing the agreement, left the project; they did not have any evidence or did not participate in any activities offered by the program ACTYBOSS. 90 children (48 students in Inca High School and 42 students in Bendinat High School) fulfilled inclusion criteria and accepted to participate in the study and thus were included in the study. At study enrollment the mean age $( \pm \mathrm{SD})$ of the participants was $13.9 \pm 1.1$ years, their mean BMI was $22.6 \pm 4.2 \mathrm{~kg} / \mathrm{m}^{2} ; 40.3 \%$ of the participants were boys, and $14 \%$ of the children were non-Caucasian.

We have established three different groups of children based on the mean exposure of hours each week participating in ACTYBOSS:

Group 127 children who participated in the activities until the end of the intervention and did more than $3 \mathrm{~h} /$ week of exercise;

Group 229 children who took part in the intervention but their level of attendance was less than $3 \mathrm{~h}$ per week;

Group 334 children who, despite signing the informed consent, abandoned the study before the first day of activities.

Assistance to the ACTYBOSS program was $6.9 \pm 3.6 \mathrm{~h} /$ week for Group 1, $2.1 \pm 0.9 \mathrm{~h} /$ week for Group 2, and $0.3 \pm 0.14 \mathrm{~h} /$ week for Group 3.

There were no statistically significant differences in any of the anthropometric variables at baseline compared to 6 months follow-up after the intervention (table 1). None of the biochemical or hormonal parameters showed significant changes (fig. 2,3). Waist circumference percentage body fat, and percentage lean mass are presented in figure 4 . There were no significant interactions by sex; therefore, data are shown with values gathered from boys and girls combined. We found a high proportion of overweight (above $85 \%$ percentile) children in our study population (40.3\%), with $14.5 \%$ of them being obese (above 95\% percentile). Remarkably, Group 1 presented a greater proportion of obese children compared to Group 2 and Group 3 (Group 1, 16\%; Group 2 $14.3 \%$, Group 3, 12.5\%).

Despite being a pilot study, we noticed some trends suggesting beneficial changes in \% muscle mass $(+3.4 \%)$, and 
systolic blood pressure $(-7.7 \mathrm{~mm} \mathrm{Hg})$ over the 6 months of intervention in the high assistance group (Group 1), which deserve special attention. The intervention group (Group 1) showed a higher increase in muscle mass compared to the children who did not start the study (Group 3) (Group 1

A

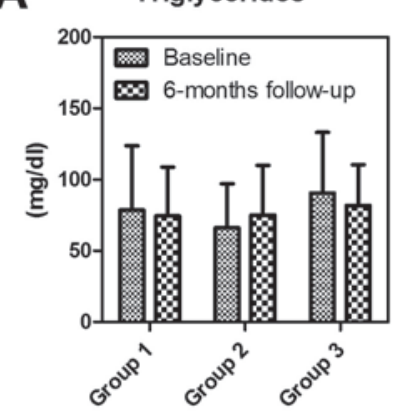

C

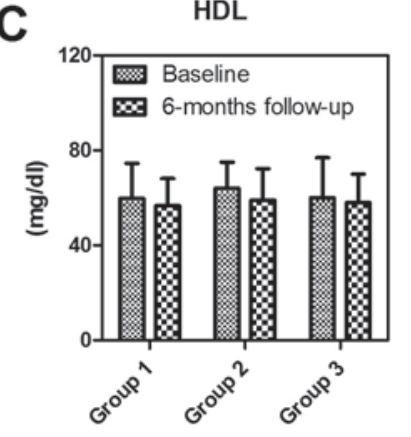

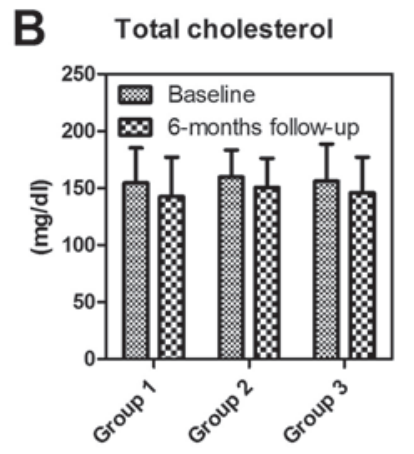

D

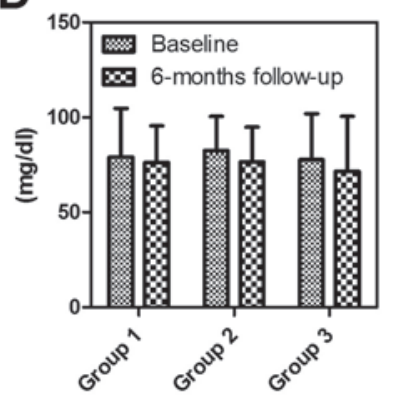

$+3.4 \%$; Group $3+1.1 \%$ ) (fig. $4 \mathrm{C}$ ). The effect sizes in other outcomes suggest that a larger trial with greater statistical power is also warranted.

In regards to the effect of the intervention on physical fitness, our data showed improvement in all parameters tested (table 2). We noticed that Group 1 (intervention group) had an improvement of $0,5 \mathrm{~s}$ in speed compared to themselves before the intervention and also performed better than any of the two other groups. We also noticed and improvement in flexibility of almost $3 \mathrm{~cm}$ in Group 1. In the evaluation of the coordination characteristics, Group 1 also showed a clear improvement ( $8 \mathrm{~s}$ over a total of $25 \mathrm{~s}$ of work, improvement of $32 \%$ ) as a consequence of the intervention.

Interestingly, we observed a significant positive correlation between the amount of hours of assistance to the activities provided in the ACTYBOSS program and body weight at baseline of the participants $\left(\mathrm{R}^{2}=0.309, \mathrm{p}=0.015\right)$ that was especially strong in those who showed a regular assistance to the program (Group $1, \mathrm{R}^{2}=0.706, \mathrm{p}=0.000$ ). Group 1 also demonstrated a significant correlation between assistance and baseline BMI $\left(\mathrm{R}^{2}=0.529, \mathrm{p}=0.007\right)$ and fat mass $\left(\mathrm{R}^{2}=0.520\right.$, $\mathrm{p}=0.008)$.

\section{Discussion}

The goal of the pilot project ACTYBOSS was to test the feasibility and acceptability of an incentive-driven, after-school program intended to promote physical activity and healthy lifestyles in children aged 11-14 years old.

Fig. 3. Baseline and 6 month follow-up lipid profile results.

Fig. 4. Waist circumference percentage body fat, percentage lean mass results.
A Waist circumference

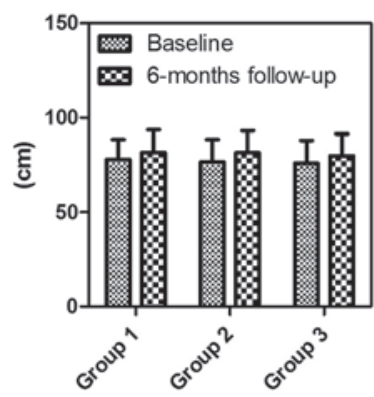

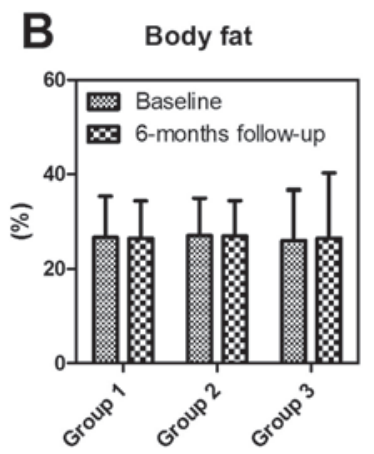

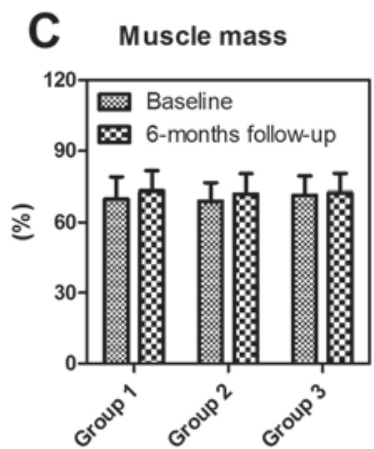

Table 2. Characteristics of skill-related fitness tests evaluated at baseline and after 6-months of intervention

\begin{tabular}{|c|c|c|c|c|c|c|c|c|c|}
\hline & \multicolumn{3}{|l|}{ Baseline } & \multicolumn{3}{|c|}{ 6-months follow-up } & \multicolumn{3}{|c|}{ Difference (and 95\% CI) at follow-up } \\
\hline & Group 1 & Group 2 & Group 3 & Group 1 & Group 2 & Group 3 & Group 1 & Group 2 & Group 3 \\
\hline Speed, s & $11.3 \pm 1.1$ & $11.7 \pm 0.7$ & $10.9 \pm 0.9$ & $10.8 \pm 0.9$ & $11.8 \pm 0.9$ & $10.8 \pm 0.8$ & $-0.5(-0.9 ;-0.1)$ & $0.1(-0.4 ; 0.7)$ & $-0.1(-0.9 ; 0.7)$ \\
\hline Agility, s & $13.8 \pm 1.9$ & $15.6 \pm 1.3$ & $13.1 \pm 1.1$ & $13.8 \pm 2.3$ & $16.2 \pm 2.3$ & $14.2 \pm 3.6$ & $0.0(-1.2 ; 1.2)$ & $0.6(-1.2 ; 2.4)$ & $1.1(-3.0 ; 5.2)$ \\
\hline Coordination, s & $34.2 \pm 7.7$ & $37.3 \pm 7.3$ & $32.4 \pm 1.6$ & $26.1 \pm 6.2$ & $28.8 \pm 6.9$ & $34.7 \pm 6.5$ & $-8.1(-10.6 ;-5.7)$ & $-8.5(-12.7 ;-4.3)$ & $2.2(-14.9 ; 19.4)$ \\
\hline Flexibility, cm & $25.5 \pm 7.5$ & $26.0 \pm 7.2$ & $30.0 \pm 2.6$ & $28.2 \pm 6.3$ & $28.6 \pm 6.1$ & $30.0 \pm 6.9$ & $2.7(0.8 ; 4.6)$ & $2.6(0.4 ; 4.9)$ & $0.0(-11.0 ; 11.0)$ \\
\hline
\end{tabular}

All results are expressed as mean $\pm \mathrm{SD}$. CI = Confidence interval. Group 1, $\mathrm{n}=11-19$; Group 2, n = 9-12; Group 3, n= 3-4. 
To our knowledge, other studies quoted in our manuscript, have used economical incentive in obese adults. Also there are a few studies, which give prizes as a reward for participating in the activity. However, we are not aware of any study where children are eligible to different prizes based on the number of hours during which they exercise.

There is controversy in the literature regarding the benefits of school-based physical activity interventions in preventing the increasing prevalence of childhood obesity. A recent meta-analysis has shown that school-based physical activity interventions do not improve body composition [16]. There is however agreement in the literature that physical activity should be promoted within schools and that it is an important component of healthy lifestyle [17].

After-school physical activity programs have the potential to improve aerobic fitness and body composition [10, 12, 15, 18]. However, one of their main limitations is to keep children motivated to stay in the study. The novel feature of ACTYBOSS is its emphasis on incentives and rewards. The target population for our intervention was the least active children who, due to different reasons (less integrated in social networks, belonging to families with lower socio-economic status), were more susceptible to develop overweight. In fact, participation on federated sports or attendance to any afterschool physical activity class (more than $3 \mathrm{~h}$ /week) was an exclusion criterion. Intriguingly, Group 1, formed by the children that showed a stronger commitment to the program, displayed higher rates of obesity at baseline, and the amount of time they invested in the ACTYBOSS activities was proportional to their BMI and amount of fat. Although we do not own objective data that could explain this phenomenon, it is appealing to hypothesize that children have a high awareness of their excess body weight and are therefore keen to participate in efforts leading to an improvement in their health status. We also propose that the same nature of the ACTYBOSS activity package, consisting on noncompetitive, social physical activity, helps to motivate this more socially fragile group into participation. We believe that the nature of the motivation and commitment to this type of program in relation to body weight deserves further investigation.

The main contributions and strengths of the study are as follows: The ACTYBOSS program caused changes in physical fitness and body composition (measured by bioimpedance), parameters which have not been routinely measured in previous studies [13,19-21], and which could improve the children's metabolic profile and reduce the risk of childhoodonset type 2 diabetes. We did not observe significant changes in BMI or fat mass; however, this was not an unexpected outcome, given the results observed in previous school-based interventions [9]. Even though this is relevant, we believe that ACTYBOSS main interest is the study design, based on the use of incentives and the stimulation of a sense of responsibility, where children, parents, schools, sponsors, and society all join efforts and subsequently obtain a positive feedback from the intervention. An important novelty of this study was that the children started the program at their own initiative, after reviewing the pros and cons of participating in it. Their commitment was rewarded with prizes, and they also had fun participating in ACTYBOSS. There was no pressure exerted by the school or the parents to get the children involved in the initiative. ACTYBOSS was well received by students who, in addition to having fun while exercising, learned the positive effects of physical activity on their health. Importantly, they started to create a social net (which in many cases they lacked of previously to their engagement in the study) that contributed to set up activities during the weekend and make them feel better at school. Especially rewarding was our ability to engage children who previously were uninterested in sports in becoming excited about the program.

Our intervention was also supported by many parents who welcomed the fact that their children started to exercise in a healthy and safe environment, free of charge in the afternoon, right after their regular school schedule. The after-hours sport activities that schools usually offer are competitive sports, where children are federated, and there is a monthly fee. Parents also appreciated the peace of mind (and extra-time) that our intervention represented to them. We also placed special effort in getting them involved in the program. We organized two lectures and two workshops for parents. In an attempt to obtain maximum participation we provided extra-points to the children whose parents/tutors attended our lectures.

The two schools that participated and their faculty also welcomed the program. They were very aware of the problem of obesity and appreciated being part of a scientific project directed by the University Hospital and supported by the Balearic Islands Health and Education Departments.

In addition to children, parents and schools, the fourth major component of this intervention were the sponsors who provided the gifts. With the help of an advertising company (Xternaliza) it was not difficult to get local businesses interested in the project. All of them provided free merchandise in exchange for visibility of their products and companies through our webpage and activities. We believe there was also an important component of altruism involved, given the social relevance that the problem of obesity has acquired.

The limitations of this study include the lack of a formal control group, the relatively small sample size and the short period of intervention. However, we obtained important data to support that the intervention is very well accepted by children, parents, and schools. The strong support from sponsors helped to make the intervention appealing to get children enrolled in the program. However, we believe that the social interaction and the amusement were the main facts that kept children coming. It is important to point out that more than 20 children (who originally had declined to participate) asked to be included in the program within the first month of the study, given the positive comments from their peers. Although testimonials from parents suggest that program parti- 
cipants remained active during the summer after the conclusion of the study, we did not obtain that set of data. However, previous studies have shown that during the summer the beneficial effect of the previous year's participation on fitness and $\%$ body fat was lost [15].

Financial incentive-based approaches for weight loss have been previously shown to be effective in causing weight loss in obese adults $[22,23]$. However, to our knowledge ACTYBOSS is the first study that evaluates the effect of an incentive-driven exercise and nutritional program, as an intervention to reduce body weight in children, in an after-school format.

We describe here a novel school intervention program, based on an incentive-driven physical and nutritional advice, which resulted in beneficial effects on anthropometrical measurements and level of fitness in the children who participated. This pilot program was well accepted by the children who decided to enroll. Ideally, programs such as ACTYBOSS may help to introduce inactive children to the benefits of physical activity and potentially lead to continued involvement in sports.

Further studies with longer follow-up periods are needed to assess the efficacy of this type of incentive-driven health interventions and to determine whether they constitute a fea- sible, acceptable and efficacious approach to apply as obesity prevention and treatment initiatives. A follow-up prospectively randomized controlled year-round study, with a larger student sample, is now being developed.

\section{Acknowledgements}

This study was funded by the Conselleria de Salud (Dirección General de Salud Publica, Govern de les Illes Balears) and the Conselleria de Economia (Dirección General de Investigación, Desarrollo Tecnológico e Innovación, Govern de les Illes Balears) and CAIBER (ISCIII, Ministerio de Innovación, Gobierno de España). We would like to acknowledge SD Assessors S.A. for their support setting up the web application and ID cards. The authors thank the Bendinat (Calvià, Spain) and Berenguer d'Anoia (Inca, Spain) High school students who participated in this study as well as their parents and teachers. Special thanks to the sponsors of the study for their generous contributions. The corresponding author had full access to all the data in the study and had final responsibility for the decision to submit for publication. No potential conflicts of interest were reported.

\section{Disclosure Statement}

The authors have nothing to disclose.

\section{References}

1 Lobstein T: The prevention of obesity in children. Pediatr Endocrinol Rev 2004;1(suppl 3):471-475.

$\checkmark 2$ Aranceta-Bartrina J, Serra-Majem L, Foz-Sala M, Moreno-Esteban B: Prevalence of obesity in Spain (in Spanish). Med Clin (Barc) 2005;125:460-466.

3 St Leger LH: The opportunities and effectiveness of the health promoting primary school in improving child health - a review of the claims and evidence. Health Educ Res 1999;14:51-69.

$\checkmark 4$ Eaton DK, Kann L, Kinchen S, Ross J, Hawkins J, Harris WA, Lowry R, McManus T, Chyen D, Shanklin S, Lim C, Grunbaum JA, Wechsler H: Youth risk behavior surveillance - United States, 2005. MMWR Surveill Summ 2006;55:1-108.

5 Katz DL, O'Connell M, Yeh MC, Nawaz H, Njike V, Anderson LM, Cory S, Dietz W: Public health strategies for preventing and controlling overweight and obesity in school and worksite settings: a report on recommendations of the task force on community preventive services. MMWR Recomm Rep 2005;54:1-12.

6 Pate RR, O'Neill JR: After-school interventions to increase physical activity among youth. Br J Sports Med 2009;43:14-18.

7 Summerbell CD, Waters E, Edmunds LD, Kelly S, Brown T, Campbell KJ: Interventions for preventing obesity in children. Cochrane Database Syst Rev 2005:CD001871.

8 Epstein LH, Goldfield GS: Physical activity in the treatment of childhood overweight and obesity: current evidence and research issues. Med Sci Sports Exerc 1999;31(suppl):S553-559.

$\checkmark$ Council on Sports Medicine and Fitness and Council on School H: Active healthy living: prevention of childhood obesity through increased physical activity, Pediatrics 2006;117:1834-1842.
10 Pate RR, Davis MG, Robinson TN, Stone EJ, McKenzie TL, Young JC: Promoting physical activity in children and youth: a leadership role for schools: a scientific statement from the American Heart Association Council on nutrition, physical activity, and metabolism (Physical Activity Committee) in collaboration with the Councils on Cardiovascular Disease in the Young and Cardiovascular Nursing. Circulation 2006;114:1214-1224.

11 Peterson KE, Fox MK: Addressing the epidemic of childhood obesity through school-based interventions: what has been done and where do we go from here? J Law Med Ethics 2007;35:113-130.

12 Weintraub DL, Tirumalai EC, Haydel KF, Fujimoto M, Fulton JE, Robinson TN: Team sports for overweight children: the Stanford sports to prevent obesity randomized trial (sport). Arch Pediatr Adolesc Med 2008;162:232-237.

13 Jansen W, Raat H, Zwanenburg EJ, Reuvers I, van Walsem R, Brug J: A school-based intervention to reduce overweight and inactivity in children aged 6-12 years: study design of a randomized controlled trial. BMC Public Health 2008;8:257.

14 DeStefano RA, Caprio S, Fahey JT, Tamborlane WV, Goldberg B: Changes in body composition after a 12-wk aerobic exercise program in obese boys. Pediatr Diabetes 2000;1:61-65.

15 Gutin B, Yin Z, Johnson M, Barbeau P: Preliminary findings of the effect of a 3-year after-school physical activity intervention on fitness and body fat: the Medical College of Georgia Fitkid Project. Int J Pediatr Obes 2008;3(suppl 1):3-9.

16 Harris KC, Kuramoto LK, Schulzer M, Retallack JE: Effect of school-based physical activity interventions on body mass index in children: a metaanalysis. CMAJ 2009;180:719-726.
7 Brown T, Summerbell C: Systematic review of school-based interventions that focus on changing dietary intake and physical activity levels to prevent childhood obesity: an update to the obesity guidance produced by the national institute for health and clinical excellence. Obes Rev 2009;10: 110-141.

18 Martinez Vizcaino V, Salcedo Aguilar F, Franquelo Gutierrez R, Solera Martinez M, Sanchez Lopez M, Serrano Martinez S, Lopez Garcia E, Rodriguez Artalejo F: Assessment of an afterschool physical activity program to prevent obesity among 9- to 10-year-old children: a cluster randomized trial. Int J Obes (Lond) 2008;32:12-22.

19 Kelder S, Hoelscher DM, Barroso CS, Walker JL, Cribb P, Hu S: The Catch Kids Club: a pilot afterschool study for improving elementary students' nutrition and physical activity. Public Health Nutr 2005;8:133-140.

20 Singh AS, Chin APMJ, Brug J, van Mechelen W: Dutch obesity intervention in teenagers: effectiveness of a school-based program on body composition and behavior. Arch Pediatr Adolesc Med 2009; 163:309-317.

21 Warren JM, Henry CJ, Lightowler HJ, Bradshaw SM, Perwaiz S: Evaluation of a pilot school programme aimed at the prevention of obesity in children. Health Promot Int 2003;18:287-296.

22 Hubbert KA, Bussey BF, Allison DB, Beasley TM, Henson CS, Heimburger DC: Effects of outcomedriven insurance reimbursement on short-term weight control. Int J Obes Relat Metab Disord 2003;27:1423-1429.

23 Volpp KG, John LK, Troxel AB, Norton L, Fassbender J, Loewenstein G: Financial incentivebased approaches for weight loss: a randomized trial. JAMA 2008;300:2631-2637. 